\title{
Mujeres y sociabilidad pueblerina en Colonia Caroya (Provincia de Córdoba). Club Juventud Agraria Colón, 1932-1942
}

\author{
[Women and Sociability in a Small Town: Colonia Caroya (Province of \\ Córdoba): Club Juventud Agraria Colón, 1932-1942]
}

\author{
Eugenia Sánchez \\ (Universidad Nacional de Córdoba) \\ meugesanchez@gmail.com
}

\begin{abstract}
Resumen
El presente trabajo pretende contribuir al estudio de las mujeres en el espacio público a partir de la reconstrucción y análisis de la participación $\mathrm{y}$ sociabilidad de las mismas en un pueblo de Córdoba (Argentina) durante la década de 1930, Colonia Caroya. Se contextualizará la participación de éstas en el marco de una sociabilidad pueblerina a partir del estudio de espacios de participación que les fueron habilitados desde una asociación recreativa. Se analizarán los años fundacionales de dicha institución, durante un periodo en el que se observan cambios se experimentaron en la sociedad argentina, principalmente en la participación política y sus espacios de sociabilidad. Se sostiene que el estar, permanecer, compartir experiencias y participar activamente en la asociación permitió a estas mujeres de Clonia Caroya vivir algunas experiencias de tintes democráticos e igualitarios, que produjeron modificaciones de sus estilos de vida.
\end{abstract}

Palabras clave: Mujeres - Sociabilidad pueblerina Vida cotidiana

\begin{abstract}
This paper attempts to contribute to the study of women in public space by analyzing and reconstructing their participation and sociability in a small town from Córdoba (Argentina) during the 1930s, Colonia Caroya. Their participation will be contextualized in a village-sociability framework through studying the spaces of participation they were allowed to them in a recreational association. The institution's founding years will be analyzed here during a period in which many changes were experienced in Argentinian society, mainly regarding female political participation and its spaces of sociability. It is argued here that the fact of being in this association, spending time together, sharing experiences, and participating actively allowed those women from Colonia Caroya to experience democracy and equality, altering in this way meaningfully their lifestyles.
\end{abstract}

Keywords: Women - Small town sociability Everyday life

Recibido: 27/03/2017

Evaluación: 24/05/2017

Aceptado: 06/07/2017

Anuario de la Escuela de Historia Virtual - Año 9 - N 13 - 2018: pp. 67-87.

ISSN: 1853-7049

http://revistas.unc.edu.ar/index.php/anuariohistoria 
68 | Mujeres y sociabilidad pueblerina en Colonia Caroya...

\section{Mujeres y sociabilidad pueblerina en Colonia Caroya (Provincia de Córdoba). Club Juventud Agraria Colón, 1932-1942}

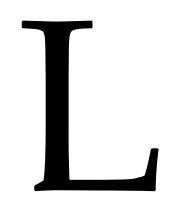

a Nueva Historia Social se caracteriza, a grandes rasgos, por su interés en "reconstruir cómo la gente vivió los condicionamientos estructurales y las transformaciones del pasado a través de diversas estrategias individuales o colectivas, interesándose igualmente por las representaciones elaboradas por diferentes sujetos sociales sobre esas experiencias vitales" (Moreyra, 2000, p. 13). Gracias a esta especial atención por los sectores otrora olvidados por la historiografía, ha sido posible rescatar a las mujeres como sujetos históricos, recuperando su capacidad creativa y estratégica. Este interés por las mujeres también ha sido el resultado de su creciente participación política, gracias a los movimientos feministas contemporáneos. Muchos de los estudios que se vienen realizando en las últimas décadas sobre las mujeres evidencian también la historicidad de los vínculos entre los sexos y el carácter relacional de la categoría de género (Aguado, 2000; Palermo, 2008; Salomón Chéliz, 2006; Scott, 1990; Segura Graiño, 2006). Por ello, definimos aquí al género en términos de lo señalado por Joan Scott (1990), es decir, como un elemento constitutivo de las relaciones sociales basadas en las diferencias que distinguen a los sexos y, a la vez, como una forma primaria de relaciones significantes de poder.

La mayoría de los estudios sobre vida cotidiana coinciden en que en la Argentina, durante la primera mitad del siglo XX, se produjeron cambios en la condición femenina. Sin embargo, en general, las investigaciones han abordado estas transformaciones a partir del análisis de las trabajadoras de espacios urbanos, desentrañando sus estrategias en el marco de relaciones sociales patriarcales y capitalistas (Viel Moreira, 2005; Lobato, 2007; Bosch Alessio, 2012; Remedi, 2014). En estos análisis, se destaca la existencia de tensiones entre las convenciones sociales acerca de los roles de género y la propia experiencia de las mujeres que transitaban por ámbitos tradicionalmente considerados masculinos. Dora Barrancos (1999), en un estudio pionero sobre la moralidad y las conductas sexuales de las trabajadoras en las grandes ciudades del país durante el período de entreguerras, señala que, si bien sobre las mismas siguieron operando mecanismos de censura, las trabajadoras fueron alcanzadas por los nuevos aires de moralidad del siglo XX. Otras investigaciones ayudan a complejizar aún más el análisis propuesto por Barrancos. En un trabajo reciente de Paula Bontempo y Graciela Queirolo (2012) sobre las "jóvenes dactilógrafas" de los años veinte, las autoras sostienen que los nuevos espacios femeninos significaron una irrupción y desafío para la sociedad patriarcal. Si bien estas trabajadoras administrativas fueron objeto de representaciones que las ridiculizaban, simultáneamente se destacaba su mayor independencia social y económica. En el contexto de 
la época, esto habría significado un verdadero desafío a la subordinación femenina. Estas investigaciones nos permiten entrever que el análisis de los ámbitos y formas de sociabilidad femenina durante el período de entreguerras es crucial para comprender los cambios operados en la condición femenina en esos años. En primer lugar, porque fueron producto y, en algunos casos, catalizadores de las transformaciones producidas en las relaciones entre hombres y mujeres. En segundo lugar, porque el análisis sistemático de dichas cuestiones posibilita detectar las estrategias y márgenes de acción de las mujeres en el contexto de una sociedad que resistía las mutaciones que se estaban introduciendo.

Consideramos que las perspectivas previas favorecen los proyectos tendientes a explorar espacios de sociabilidad femenina e iluminar la heterogeneidad y particularidades de la vida local. De tal modo, este trabajo pretende ser una contribución a ello a partir del estudio de espacios de sociabilidad transitados por mujeres del interior. En este caso, no se trata de trabajadoras, pero sí de mujeres con notable participación en una asociación de caracteres modernos. Así, nos alejaremos de los espacios y sujetos que tradicionalmente fueran abordados por la historiografía interesada en la temática y analizaremos, en cambio, mujeres hijas de pequeños propietarios de tierras que trabajaban en el seno familiar (sin recibir salario por ello) en un pueblo del norte de Córdoba.

Consideramos que el examen de los vínculos de género en una asociación del interior del país que convocó a hombres y mujeres nos puede otorgar pistas sobre los estilos de sociabilidad pueblerina y sobre los cambios producidos en las relaciones de poder existentes en la sociedad. En este sentido, el presente trabajo pretende contribuir al estudio de las mujeres del interior del país, reconstruyendo y examinando los ámbitos y formas de sociabilidad de las mismas en un pueblo cordobés durante la década de 1930, Colonia Caroya. Para ello, se indagarán los primeros diez años de existencia del Club Juventud Agraria Colón (CJAC), asociación ligada a la Federación Agraria Argentina (FAA), ya que este se nos revela como indicador $y$, muchas veces, motor de las modificaciones que se dieron en el rol de la mujer y su sociabilidad en el espacio público caroyense. El estar, permanecer, compartir y participar en un club les permitió a las mujeres caroyenses vivir experiencias de tintes democráticos e igualitarios, lo que no implicó que las relaciones patriarcales no siguieran reproduciéndose, sino que en las mismas se introdujeron modificaciones relevantes. El análisis de las mujeres en el espacio público caroyense se realizará contextualizando su participación en el marco de una sociabilidad pueblerina (categoría que definiré más adelante) a partir de la reconstrucción de espacios de participación que les fueron habilitados desde el club durante la década del treinta.

En línea con nuestras inquietudes por indagar estas temáticas en lugares del interior del país y, en especial, en espacios demográficamente más pequeños que las grandes ciudades, Patricia Roggio (2009) realiza una relevante contribución en esa dirección al estudiar a las mujeres rurales de Colonia Caroya durante el período 1890-1950. Este es 
70 I Mujeres y sociabilidad pueblerina en Colonia Caroya...

el único trabajo que aborda a este actor histórico y, si bien no hace foco en la sociabilidad, identifica a las mujeres de Caroya como productoras y reproductoras de fuerza de trabajo familiar y posibilita aproximarnos a aspectos de su vida cotidiana. A partir de sus entrevistas, Roggio deja entrever que durante el período en estudio predominaban en Caroya organizaciones familiares de carácter patriarcal y relaciones endogámicas. Sin embargo, este trabajo revela muy poco sobre qué márgenes de acción tuvieron estas mujeres más allá de su rol productivo.

$\mathrm{El}$ análisis de este artículo fue realizado a partir de lecturas bibliográficas, del relevamiento de las actas de reuniones ordinarias de la comisión directiva del CJAC (AROCDCJAC), de las reuniones extraordinarias de dicha comisión (ARECD-CJAC), de los Estatutos de la Central de Clubes Juventud Agraria Argentina y Clubes Juventud Agraria (ECCJAAyCJA) y del Registro de Socios del CJAC (RS-CJAC). Asimismo, abordé los testimonios de cuatro contemporáneas que me ayudaron a ratificar varias de mis hipótesis y a provocar nuevos interrogantes. También, realice encuestas a dos socias fundadoras de la asociación: Elvira Trevisani en 2010 y 2014 y Sara Morandini en 2010, a Nelly Coppetti en 2015 (caroyense nacida en 1933 que vivió en la localidad hasta fines de la década de 1940) y a Elba Chalup en 2015 (hermana de Alfredo Chalup, jesusmariense socio de la institución). En un primer momento, reconstruyo la historia de la localidad haciendo hincapié en su vínculo con la inmigración de fines del siglo XIX. Luego, realizo una descripción sociológica de los socios y socias del CJAC. Finalmente, describo en el espacio del club aquellas características esenciales que hicieron a la sociabilidad pueblerina para estudiar los lugares que fueron ocupados por mujeres, intentando detectar vestigios de cambios en la participación y el rol de las mismas en el espacio público de un pueblo.

\section{Colonia Caroya inmigrante}

Colonia Caroya es una localidad ubicada a $50 \mathrm{~km}$ al norte de la ciudad de Córdoba y su historia está ligada a una tierra habitada por friulanos. Fue una colonia italiana organizada por el Estado nacional en una zona alejada del proceso colonizador desarrollado esencialmente en la pampa húmeda. Desde 1878 comenzaron a llegar al lugar inmigrantes italianos de la región del Friuli-Venezia-Giulia. Al igual que la colonia Sampacho, al suroeste de la provincia, se trató de un espacio urbano planificado y pensado desde el Estado nacional como un asentamiento de frontera contra el indio y apto para la producción agropecuaria destinada a abastecer el mercado mundial (Arcondo, 1996). Sin embargo, la producción de cereales no fue tan exitosa como se pretendió. Los caroyenses se vieron obligados a cambiar su producción y comenzaron a cultivar vides y diversos árboles frutales. La industria vitivinícola prosperó en algunas pequeñas bodegas familiares y otras de mayor envergadura productiva. En las quintas trabajaba todo el grupo 
familiar, hombres, mujeres, adultos, jóvenes y niños. Además, para las etapas de recolección, llegaban a la localidad gran cantidad de trabajadores provenientes del norte de la provincia. ${ }^{1}$

Entre 1887 y 1911, Colonia Caroya gozó de autonomía municipal, hasta que el gobierno provincial decretó la incorporación del municipio caroyense al de Jesús María, aduciendo acefalía municipal. Hacia 1918 la provincia consideró y aceptó un petitorio de los pobladores de la Colonia solicitando la separación administrativa. Dicha medida fue festejada en Caroya con actos públicos en los que se dieron discursos en friulano y se festejó "el retorno a la normalidad". Mientras tanto, en Jesús María se realizaron protestas, ya que el decreto también declaraba acéfalo a este municipio y nombraba una Comisión Administradora (Núñez, 1978). Estos conflictos calaron hondo en la memoria colectiva de los caroyenses y es importante tenerlos presentes para analizar los vínculos establecidos entre los vecinos de ambas localidades.

En Caroya existió una gran cantidad de pequeños propietarios que fueron preponderantes hasta 1940 (Roggio, 2009). Si seguimos el planteo de Pierre Bourdieu (1990) sobre el campo social y las "clases probables", se puede concebir que estos pequeños propietarios y algunos medieros y arrendatarios se fueron constituyendo paulatinamente en los sectores con mayor capital económico del pueblo y un importante capital cultural, simbólico y social. Esa acumulación, lograda por propiedad o arrendamiento de la tierra, en algunos casos, se extendía a la propiedad de la maquinaria, la que muchas veces se alquilaba a productores menores. Esa acumulación era disputada por otros actores agrarios, como los medieros y arrendatarios e, incluso, por los trabajadores estables. Pero si en gran medida las diferencias de clase en el pueblo dependían de la posesión y propiedad de tierras y tecnología, también involucraban otras cuestiones de carácter cultural y simbólico.

El pueblo para la entreguerras presentaba una actividad asociativa muy importante en comparación a otras ciudades del norte cordobés. Hacia 1930 existían asociaciones católicas y laicas. Entre estas últimas, encontramos a las cooperadoras escolares, el Bochas Sport Club, la seccional local de la FAA, la cooperativa “La Caroyense" y el CJAC. Las últimas tres instituciones se encontraban ligadas a la FAA. Los contactos entre la entidad agraria y los colonos de Caroya se iniciaron en 1926 por intermedio de un vecino caroyense corresponsal de La Tierra, periódico publicado por la FAA (Solveira, 2012). En febrero de 1930, los colonos constituyeron la seccional caroyense de la FAA y comenzaron a trabajar en la organización de una cooperativa para que industrializara la producción de la uva y demás frutas. Para ello solicitaron asesoramiento a la FAA. Para la asociación agraria era muy prometedora la formación de una cooperativa dada la ubicación del pueblo, con fácil comunicación con el norte cordobés, y su base poblacional, muy

\footnotetext{
${ }^{1}$ N. Copetti, comunicación personal, 23 de abril de 2015. Jesús María.
} 
72 I Mujeres y sociabilidad pueblerina en Colonia Caroya...

similar a los de la Pampa Gringa.

El CJAC fue una consecuencia de la relación que se estableció entre los productores que conformaron la cooperativa "La Caroyense" y la FAA. Los clubes agrarios de todo el país se rigieron por los Estatutos emanados de la Central de Clubes Juventud Agraria, la cual tenía su sede en Rosario y se mantuvo con el aporte mensual que le enviaban los diversos clubes extendidos por el país. La Central se encargó de realizar congresos cada dos años a fin de comunicar y debatir sobre distintas cuestiones. Estaba dirigida por un Consejo Central elegido por simple mayoría de votos de sus afiliados y la mitad de sus miembros se renovaba cada año. Por consiguiente, el consejo estuvo conformado por delegados de distintos clubes electos en los congresos anuales. En la primera reunión llevada a cabo en Colonia Caroya concurrieron al local de la cooperativa unos cincuenta jóvenes entre varones y mujeres y en la asamblea constitutiva se eligió la primera comisión directiva (CD), compuesta de igual cantidad de hombres y mujeres. ${ }^{2}$

\section{Los socios y socias del CJAC}

Cuando el CJAC inició sus actividades, los estatutos exigían que los socios fuesen jóvenes solteros, hijos/as de padres dedicados a actividades relacionadas con el campo. A partir de las conversaciones con Elvira Trevisani podemos sugerir que las y los jóvenes invitados por el presidente de la FAA -Esteban Piacenza- a la primera asamblea constituyente eran hijos de inmigrantes italianos, pequeños productores afiliados a la FAA y socios de la cooperativa. Durante toda la década, las autoridades trataron de mantener cierto control sobre las nuevas afiliaciones. De ese modo, estas primeras invitaciones fueron dirigidas a los miembros más jóvenes de las familias propietarias y de mejor posición económica que vivían próximos a la cooperativa. Las mujeres integrantes de las primeras $\mathrm{CD}$ pertenecían a las capas más enriquecidas de la población. Una de nuestras entrevistadas, por ejemplo, era hija de padres propietarios de tierras y dueños de maquinaria que alquilaban a otros productores. Ninguno de los primeros dirigentes de la institución tenía "necesidad" de salir a trabajar; una de ellas, era hija de la única familia que poseía un automóvil en la ciudad en el cual realizaban la propaganda de los distintos bailes que el club organizaba y, también, era dueña de una vitrola, algo muy costoso para la época. ${ }^{3}$

En los años siguientes, sin embargo, la composición de los socios fue cambiando y esas características socio-económicas solo fueron compartidas por los miembros dirigentes y con mayor actividad en el club, no así por el resto de los socios. Nuevas funciones como la formación de un equipo de fútbol sumaron personas de niveles económicos más bajos, otras como los bailes y el juego de bochas incentivaron a gente de otras localidades cercanas a acercarse al club, principalmente de Jesús María.

\footnotetext{
2 El Cooperativista, 17 de marzo de 1947, p. 3.

${ }^{3}$ E. Trevisani, comunicación personal, 20 de febrero de 2014. Colonia Caroya.
} 
Durante la década de 1930 se asociaron al CJAC un total de 316 personas, 254 hombres y 62 mujeres. ${ }^{4}$ Los vecinos que participaron en la institución fueron incrementándose durante la década, aunque no de forma gradual. Esto resulta significativo si consideramos que la población caroyense tendió a disminuir hacia los años cuarenta, momento en que se produjo una importante emigración hacia la localidad de Chilecito, La Rioja, en donde se había instalado una filial de la Cooperativa. ${ }^{5}$

La diferencia entre la cantidad de mujeres y hombres que se asociaron entre 1932 y 1942 también sufrió fluctuaciones. Entre 1932 y 1935 las mujeres representaron aproximadamente el 30\% de los asociados; entre 1936 y 1938, menos del 10\%, y en 1937, 1939, 1940, 1941 y 1942, entre un 10 y un 20\%. La masculinización del espacio fue evidente durante el trienio 1936-1939, años en que, además, las jóvenes no formaron parte de las CD. Es de destacar, sin embargo, que los valores femeninos nunca llegaron a cero y, a pesar de decrecer, el proceso de afiliación se mantuvo durante toda la década. Es relevante además el crecimiento femenino que se dio a partir de $1940,{ }^{6}$ cuando el número de ingresantes triplicó al del año anterior.

Respecto a la nacionalidad, de 63 miembros, seis en 1932 y uno en 1933 eran italianos y el resto argentinos, en los siguientes años, solo muy esporádicamente se consignó la nacionalidad y, cuando se hizo, se trató de argentinos. Los italianos fueron disminuyendo, quedando solo gente de edades avanzadas de nacionalidad europea, lo cual no quita relevancia a su trascendencia en la sociedad caroyense, fundamentalmente por la cultura y valores que transmitieron a sus descendientes, aportes claves para la sociabilidad pueblerina que se desarrolló en la localidad.

La condición de soltería para ser socio solo se mantuvo un corto tiempo y luego se abolió, puesto que impedía el ingreso de nuevos asociados y la permanencia de otros; ${ }^{7}$ modificación que, sin embargo, en las fuentes no se detalla con exactitud. El cambio es posible percibirlo en el registro de socios, donde una de las socias entre 1932-1933 y 19391941 es anotada con su apellido de soltera y, luego, en 1942, se agrega el apellido de su marido. ${ }^{8}$ La pareja había contraído matrimonio en junio de $1941,{ }^{9}$ ambos eran socios del club y él era uno de los más activos miembros de la institución. Es decir que ya para 1942 no se requería ser soltero para asociarse o mantenerse en la asociación, lo que provocó que el universo etario asociado fuera más diverso.

Por otro lado, el perfil y la formación agraria que se proponían desde la FAA se vieron

\footnotetext{
${ }^{4}$ Registro de Socios del Club Juventud Agraria Colón (RS-CJAC), Libro I, 1932-1942, pp. 1-36.

${ }^{5}$ El Censo Nacional de 1914 registra 3.540 habitantes en Jesús María y Colonia Caroya cuando los municipios estaban unidos, mientras que el de 1947 contabiliza 677 personas -331 varones y 346 mujeres- en Caroya.

${ }^{6}$ Actas de Reuniones Ordinarias de la Comisión Directiva del Club Juventud Agraria Colón (AROCDCJAC), Libro II, núm. 172, 1 de septiembre de 1940, p. 63.

${ }^{7}$ E. Trevisani, comunicación personal, 20 de febrero de 2014. Colonia Caroya.

${ }^{8}$ RS-CJAC, Libro I, 1932-1942, pp. 1-36.

9 AROCD-CJAC, Libro II, núm. 197, 14 de mayo de 1941, p. 99.
} 
74 | Mujeres y sociabilidad pueblerina en Colonia Caroya...

condicionados por los propios intereses de los jóvenes del club, que no siempre se inclinaron por los mismos que la entidad madre. Si bien la mayoría de los socios eran hijos e hijas de padres que desarrollaban alguna tarea vinculada al agro, esto no era excluyente. Por ejemplo, mientras el padre de Elvira tenía una pequeña quinta, era accionista de la FAA y se dedicaba a alquilar máquinas para trabajar el campo, ${ }^{10}$ los padres de Alfredo Chalup, asociado en 1940, eran dueños de un comercio en Jesús María. ${ }^{11}$

La FAA pretendió educar a los jóvenes en tópicos agrarios. ${ }^{12}$ No obstante, durante toda la década no se dictaron cursos ni conferencias que enseñaran temas relacionados con la vitivinicultura u otras técnicas agrícolas que pudieran contribuir a desarrollar la capacitación de los productores. No sucedió lo mismo con las mujeres para quienes se dictaron cursos en 1934, 1935 y 1941. En 1934 y 1935 se enseñó a las socias corte y confección, ${ }^{13}$ mientras que en 1941, desde la Central de Clubes, se envió una circular a los clubes solicitando que estos contrataran a una maestra para que dictara un curso titulado "La Mujer de la Chacra", ${ }^{14}$ que comprendía la enseñanza de "quehaceres domésticos", 15 definiendo claramente cuál era el rol de la mujer de la zona rural y las divisiones de tareas entre hombres y mujeres. El CJAC requirió el dictado del curso para abril de ese año, luego de la cosecha de la uva, aduciendo que sería el momento más propicio, ya que las socias estarían más desocupadas. Esto confirma su trabajo conjunto con el varón en el campo, o en la "retaguardia". ${ }^{16}$ También ratifica lo señalado por Roggio (2009), para quien en la sociedad caroyense las mujeres de la comunidad debían desempeñar un rol en la producción y reproducción de la fuerza de trabajo. En consecuencia, la participación femenina en el club implicó la disponibilidad de más tiempo libre y, por ende, de una mayor ausencia en el seno familiar y en la producción. Esto alteró la vida cotidiana de estas mujeres quienes, además de salir de su casa para trabajar en la quinta familiar, también lo hacían para participar de otros espacios. Si bien la institución incluyó mujeres a partir estereotipos femeninos tradicionales -entre sus objetivos enunciaba la pretensión de que las jóvenes aprendiesen a ser madres y mujeres encargadas de un hogar-,$^{17}$ estas pudieron acercarse a la institución tanto por interés en las propuestas de capacitación como por la posibilidad de desarrollar una sociabilidad diferente.

La biblioteca de la asociación fue creada para satisfacer otra meta que tenía la FAA en estos clubes: la formación cultural y la "elevación moral de la juventud campesina". ${ }^{18} \mathrm{Al}$

\footnotetext{
${ }^{10}$ E. Trevisani, comunicación personal, 20 de febrero de 2014. Colonia Caroya.

${ }^{11}$ E. Chalup, comunicación personal, 5 de mayo de 2015. Colonia Caroya.

${ }^{12}$ El Cooperativista, 17 de marzo de 1947, p. 3.

${ }^{13}$ AROCD-CJAC, Libro I, núm. 64, 5 de agosto de 1934, p. 132; AROCD-CJAC, Libro I, núm. 76, 31 de marzo de 1935, p. 158.

${ }^{14}$ AROCD-CJAC, Libro II, núm. 187, 19 de enero de 1941, p. 83.

${ }^{15}$ AROCD-CJAC, Libro II, núm. 189, 29 de enero de 1941, p. 85.

${ }^{16}$ AROCD-CJAC, Libro II, núm. 187, 19 de enero de 1941, p. 83.

17 Estatutos de Central de Clubes Juventud Agraria Argentina y de Clubes Juventud Agraria (ECCJAAyCJA), art. 2, 1943.

${ }^{18}$ El Cooperativista, 17 de marzo de 1947, p. 3.
} 
mes siguiente de organizada la biblioteca, la CD compró a la Editorial Claridad \$30 en libros. ${ }^{19} \mathrm{Al}$ ser la única editorial que se menciona en las fuentes durante este período, se torna relevante describir brevemente qué contenidos editaba para aproximarnos a los intereses de los socios. La Cooperativa Editorial Claridad publicó entre 1922 y 1940 cientos de títulos de los más diversos temas y autores con precios accesibles. Juliana Cedro (2012) afirma que el proyecto Claridad se presentó como la progresiva construcción de un puente entre dos extremos del mundo del libro de aquellos años, ampliando la oferta en el mercado masivo y, a su vez, creando su demanda. La autora señala el rol militante de la editorial: todo lo publicado tenía como objetivo educar y crear conciencia en la clase trabajadora, propósito que no supuso descuidar su perfil comercial. Por añadidura, entre novelas y poesías, los socios y socias del CJAC tenían acceso a lecturas de izquierda (particularmente socialistas) y a textos que las explicaban. Con todo ello no es posible establecer una relación directa entre la propuesta editorial de Claridad y lo que los socios y socias caroyenses efectivamente leían. Además, si bien la intención de la CD fue suscribirse a una editorial de publicaciones heterogéneas y la adscripción a la editorial no se fundamentó en su propuesta socialista, no obstante, es interesante que esta propuesta cultural con una clara orientación política fuera presentada como una opción de lectura para los socios y socias. Según Elvira y Sara Morandini, los miembros de las primeras CD eran partidarios de la UCR y en todos lados hablaban de política. ${ }^{20}$

Si bien desde la FAA se propuso educar y formar a la juventud campesina en cuestiones agrarias, es posible afirmar que los socios y socias del CJAC reformularon ese contenido y perfil ligándolo a intereses y necesidades propias. Sus actividades no apuntaron a una educación en temas vinculados al campo ni a la vitivinicultura, sino que exploraron otro tipo de intereses y necesidades: la recreación, el deporte, estilos de sociabilidad establecidos por ellos mismos. Las mujeres llevaron a cabo actividades formativas que la entidad agraria proponía, pero también le imprimieron otro cariz. No solo actuaron en el club para formarse como "buenas amas de casa", sino que también encontraron en el mismo un espacio de encuentro con amigas. Esto implicó que si bien su participación fue justificada a partir de un discurso que enfatizaba la domesticidad y su vinculación con las tareas del hogar y el ámbito privado, ${ }^{21}$ de todos modos, el club habilitó un espacio público de encuentro entre los sexos. Además de compartir con los hombres las tareas agrícolas en la producción familiar, ahora también lo hacían desde un espacio de esparcimiento que suponía reglas de comportamiento más relajadas.

\footnotetext{
${ }^{19}$ AROCD-CJAC, Libro I, núm. 13, 31 de julio de 1932, p. 23.

${ }^{20}$ E. Trevisani y S. Morandini, comunicación personal, 17 de marzo de 2010. Colonia Caroya.

${ }^{21}$ Joan Scott (2000) sostiene que la ideología de la domesticidad se constituye en una serie de procesos discursivos que naturalizan la división sexual del trabajo, o la separación entre hogar y trabajo, durante el desarrollo del capitalismo industrial, al considerarla como parte de un desarrollo histórico inevitable. A partir de dichos procesos discursivos se crean identidades femeninas y masculinas.
} 
76 I Mujeres y sociabilidad pueblerina en Colonia Caroya...

\section{Las mujeres en el marco de la sociabilidad pueblerina}

Entendemos que la sociabilidad pueblerina se refiere a estilos de relaciones que entablaron los vecinos de una localidad demográficamente pequeña, en donde la inmigración ultramarina se convirtió en un elemento importante desde una perspectiva sociológica y antropológica. Los pobladores se conocían entre sí y, generalmente, tenían vínculos familiares que los conectaban. Además, compartían espacios que los congregaban a todos -la Iglesia y la plaza, principalmente- en encuentros periódicos que servían, a su vez, para reconfigurar sus vínculos. Fenómenos como el chisme y el rumor fueron constitutivos de la vida social de estos pueblos y, por lo tanto, factores claves para analizar los estilos de sociabilidad. A través de lo que "se dice" la comunidad condenaba lo curioso, lo "extraño" y daba información sesgada sobre lo que le resultaba verosímil. Los pueblerinos poseían una historia en común ligada a la fundación del lugar que permitía la construcción de un relato que incluía a algunos y excluía a "otros". El "nosotros" es el que integraba a los enunciadores de la narración y formaba parte de esa historia que los vinculaba social y culturalmente. Los "otros" eran los que, según esta mirada, no podían dar cuenta de ese pasado en común y a los cuales se les atribuía una serie de características sociales y culturales que los oponían y, en consecuencia, alejaban del "nosotros", aceptado a pesar de todos los probables conflictos internos con los que debían lidiar cotidianamente. Esta construcción de la diferencia promovió la defensa de vínculos endogámicos que se veía reforzada en la medida en que las fronteras con los "otros" se difuminaban y mixturaban.

A partir de lo relatado por Nelly Copetti y Elvira Trevisani y del análisis de los espacios de sociabilidad habilitados por el CJAC es posible identificar aspectos claves que hacen a la sociabilidad pueblerina y al rol jugado por las mujeres en su definición. Como se mencionó más arriba, una característica que hace al estilo de sociabilidad que encontramos en Caroya, es la trascendencia que tenía para la comunidad su autopercepción como integrantes de un pasado común. Otro punto es la influencia del chisme y el rumor sobre los pobladores, fenómenos que se tornaron constituyentes de la vida social e informan sobre aspectos esenciales para analizar los diferentes vínculos surgidos en un pueblo.

Desde el espacio del CJAC las mujeres caroyenses ejercieron una nueva forma de participación en el espacio público local. Pudieron votar y ser elegidas para formar parte de la dirigencia de una institución que las convocaba a participar junto a los hombres, en tiempos en que no lo podían hacer a nivel nacional, ni provincial ni municipal. En la 
primer CD, cinco de los diez cargos fueron ocupados por mujeres, incluso la presidencia. ${ }^{22}$ Entre 1935-1942, las socias no formaron parte de la CD, pero continuaron interviniendo en las diversas acciones llevadas a cabo por la asociación, ${ }^{23}$ principalmente, en la dirección de la biblioteca, en las asambleas generales y en algunas cuestiones que hacían a la organización de eventos y actividades. ${ }^{24}$

En el siguiente apartado, analizaré los espacios del CJAC ocupados por las mujeres. Lo haré a partir de la reconstrucción de los aspectos claves que hacen a la sociabilidad pueblerina, identificando los cambios y permanencias que se dieron en los vínculos entre los géneros en el interior de la asociación. Estos, a su vez, ayudan a explicar las particularidades del estilo de sociabilidad que se va consolidando en la comunidad caroyense durante la década de 1930.

La relevancia de un pasado en común en momentos de transformación

Los inmigrantes que llegaron a fines del siglo XIX y principios del XX a Caroya hablaban friulano y hacia 1930 sus descendientes hablaban castellano con una importante introducción de palabras en el idioma de sus antepasados, algo que distinguía a sus habitantes de sus vecinos criollos. ${ }^{25}$ Esta combinación en el hablar hacía presente en la cotidianeidad el pasado en común que compartían los habitantes de Caroya y, a su vez, marcaba diferencias con sus vecinos jesusmarienses. El legado inmigrante también se exteriorizaba en objetos e inmuebles que las familias habían heredado. Desde los lotes que fueron entregados y vendidos a los primeros colonos hasta aquellas pertenencias que habían cruzado el Atlántico, estos objetos reforzaron la identidad inmigrante y su cohesión comunitaria.

A pesar de que el número de inmigrantes italianos en el CJAC no era importante y además descendía con los años al compás que lo hacía la inmigración, los valores y costumbres que los caroyenses vinculaban a ese pasado inmigrante se reafirmaron en la comunidad mediante la reformulación constante de un "nosotros" frente a un "otro". Es así como la endogamia en las alianzas matrimoniales, el trabajo sacrificado y el ahorro son tópicos que forman parte de la definición de ese "nosotros" que se rescata en los relatos de Elvira y Nelly y que Patricia Roggio (2009) también identifica. Esta autora señala que las prácticas endogámicas sirvieron a la comunidad para mantener su identidad cultural, la cohesión y la diferenciación con respecto al grupo criollo hasta los años

22 AROCD-CJAC, Libro I, núm. 2, 5 de mayo de 1932, p. 4.

${ }^{23}$ Las mujeres intervinieron activamente en la organización de fiestas y veladas artísticas a pedido de los socios dirigentes del club: AROCD-CJAC, Libro I, núm. 42, 17 de septiembre de 1933, p. 77.

${ }^{24}$ AROCD-CJAC, Libro I, núm. 64, 5 de agosto de 1934, p. 132; AROCD-CJAC, Libro I, núm. 76, 31 de marzo de 1935, p. 158; AROCD-CJAC, Libro II, núm. 232, 2 de agosto de 1942, p. 161.

25 Los caroyenses denominaron "criollo" a aquellos que no descendían de inmigrantes italianos, principalmente, a sus vecinos de la localidad de Jesús María. 
78 | Mujeres y sociabilidad pueblerina en Colonia Caroya...

cincuenta, a pesar de las transformaciones sufridas por la comunidad en todos los órdenes. Las distintas CD que se sucedieron a lo largo de la década intentaron establecer ciertos controles sobre quiénes podían participar de los distintos espacios, otorgando suma importancia a la cuestión de la ascendencia italiana. El hecho de que el origen italiano haya sido defendido y valorado en el discurso y que condicionara las prácticas no quiere decir que obligaron a todos a casarse y relacionarse exclusivamente entre descendientes de italianos. Es más, se puede decir que la sociedad caroyense de los años '30 se estaba modificando y mezclando, por lo que, paulatinamente, se modernizaban sus espacios de participación. El CJAC es testimonio y motor de este proceso.

El club propició espacios de sociabilidad entre mujeres y varones caroyenses, donde se reforzaron los lazos a partir de prácticas y lazos endogámicos y xenófobos, como lo demuestran las reuniones de las CD y subcomisiones, los bailes sociales y los pic-nics, donde los controles de admisibilidad eran bastante estrictos. Pero también se crearon otros, como los campeonatos de fútbol, los bailes populares y los festejos de carnaval que transformaron las relaciones con jóvenes de localidades vecinas y entre distintas clases sociales. Todos estos lugares fueron transitados por mujeres, su presencia e interrelaciones produjeron y contribuyeron a cambiar las relaciones entre géneros y la propia experiencia de aquellas.

Las mujeres ocuparon similares espacios, pero no desarrollaron iguales tareas que los hombres. Durante toda la década, se puede observar que, al interior de la institución, se distribuyeron roles según el sexo. Entre 1932-1934, las mujeres desempeñaron cargos titulares en la $\mathrm{CD}$, asistieron a las reuniones y cumplieron un papel muy activo en la toma de decisiones. Sin embargo, en lo que se refiere a las gestiones con personas e instituciones ajenas al club los hombres eran los encargados de llevarlas a cabo, muchas veces encomendados por una de las socias. ${ }^{26}$ Lo público era visto como el ámbito masculino por excelencia, por eso eran los hombres los que debían actuar en él; sin embargo, con estas actividades las mujeres también lo estaban ocupando y transformando. A pesar de que ya no formaran parte de la $C D$, en los años siguientes las socias continuaron interviniendo en las diversas funciones llevadas a cabo por la asociación, ${ }^{27}$ principalmente en la dirección de la biblioteca a partir de 1939. Sin duda, la reincorporación de las mujeres al grupo dirigente de manera formal, respondió a la presión ejercida por estas que, desde 1935, habían sido apartadas de los cargos directivos. La experiencia durante esos primeros años en que participaron activamente cambió su forma de relacionarse con los hombres; el club se había convertido en un lugar de encuentro entre amigos/as que no se iba a abandonar. Entre 1935-1939, la presencia de un grupo de mujeres en las asambleas generales y en las reuniones de la $\mathrm{CD}$, donde ejercieron en algunas oportunidades un rol

\footnotetext{
${ }^{26}$ AROCD-CJAC, Libro I, núms. 2-7; 9; 11; 12; 16; 17; 20; 21; 23; 24; 28; 29; 30; 42; 43; 47; 50-52; 58, 1932.

${ }^{27}$ Las mujeres intervinieron activamente en la organización de fiestas y veladas artísticas a pedido de los socios dirigentes del club que generalmente les encomendaron la decoración: AROCD-CJAC, Libro I, núm. 42, 17 de septiembre de 1933, p. 77.
} 
de "representantes" de las demás socias, coadyuvó para que estas no cedieran más espacios dentro de la institución.

La biblioteca, además de presentarse como una posibilidad para ejercer un cargo directivo para las mujeres, también constituyó la primera experiencia laboral para algunas. A fines de 1942, se decidió contratar a una persona para que atendiese al público y confeccionara las actas de las reuniones de la CD junto al secretario; se presentaron dos mujeres como candidatas, resultando elegida una de las socias fundadoras y con mayor permanencia en el club, a quien se le pagaba $\$ 15$ mensuales. ${ }^{28}$ Sara Trevisani, hermana de Elvira, también atendía al público de la biblioteca, luego de que salía de su trabajo. Sara trabajó en la tienda comercial de la cooperativa hasta antes de casarse. Los comentarios de Elvira sobre su hermana nos acercan a las transformaciones que se estaban dando a nivel de las concepciones y prácticas designadas a cada sexo. Elvira nos hace notar que las mujeres solteras podían trabajar, aunque no fuesen pobres, a diferencia de lo que sucedía "en su época" ${ }^{29} \mathrm{El}$ comentario es muy interesante, ella percibió un cambio en las posibilidades que otorgaba el discurso y las prácticas sociales vigentes. Una mujer soltera y sin problemas de dinero, como Sara, podía trabajar y concurrir a un espacio compartido con amigos, lo cual seguramente la ausentaba varias horas de su casa. Cuando Elvira era soltera solo las mujeres pobres trabajaban, ella y sus amigas no lo hacían porque no lo necesitaban. Algo había cambiado para que se "permitiera" a algunas mujeres una mayor presencia en el ámbito laboral hacia 1940-1942. Este cambio quizás tenga que ver con la emigración de gran parte de la mano de obra masculina hacia una filial de "La Caroyense" instalada a principios de los '40 en La Rioja. Estos cambios también se relacionaron con la experiencia de la generación anterior y con las transformaciones mundiales y nacionales en las condiciones de la mujer, como señalaron Barrancos (1999), Bentempo y Queirolo (2012), entre otros. El relato revela este cambio de actitud, sin embargo, ello no quiere decir que todo el universo femenino caroyense tuviera esta misma experiencia.

Las reuniones ordinarias de las $\mathrm{CD}$ y de las subcomisiones también transformaron las formas de vinculación entre jóvenes de ambos sexos y sus amigos. La experiencia en la CD llevó a hombres y mujeres a vivir de forma diferente a como se vivía hasta entonces la amistad. Las jóvenes, miembros de las primeras $C D$, se conocían desde antes, vivían cerca y sus padres compartían actividades y negocios, pero las posibilidades y espacios que les brindaron las reuniones del club contribuyeron a producir cambios en las formas de vincularse y posicionarse en la comunidad caroyense. El testimonio de Elvira es bastante elocuente: “yo agradezco al club porque uno salía. Las reuniones las hacíamos el domingo a la tarde... después nos reuníamos, charlábamos... a veces la llevábamos [a la

${ }^{28}$ AROCD-CJAC, Libro II, núm. 257, 13 de diciembre de 1942, p. 205; AROCD-CJAC, Libro II, núm. 260, 10 de enero de 1943, pp. 209-210.

${ }^{29}$ E. Trevisani, comunicación personal, 20 de febrero de 2014. Colonia Caroya. 
80 I Mujeres y sociabilidad pueblerina en Colonia Caroya...

vitrola] y poníamos discos y bailábamos ahí en el club a medio de hacer, pero la barrita nuestra... si no hubiese sido eso me parece que mi vida hubiese sido muy distinta... después el fútbol, íbamos a la cancha...". ${ }^{30}$ Quiero subrayar el comentario de que su vida "hubiese sido muy distinta" y enlazarlo con parte de su testimonio donde nos cuenta que cuando Santiago Rizzi, quien fue luego su marido, le envió una carta pidiéndole ser su novio, ella le dijo que no porque quería estar con sus amigas. ${ }^{31}$ Para tomar esa decisión debió de influir sin duda su experiencia en el club donde se produjeron transformaciones notables en los estilos de sociabilidad y, por supuesto, en la concepción de la amistad. Los lazos entre amigos/as se hicieron más libres, más asiduos los encuentros: las visitas no se restringieron a los espacios hogareños donde siempre estaba presente algún familiar, sino que los encuentros pudieron tener lugar en otros ámbitos sin la "supervisión" de algún adulto u otro familiar. Por lo tanto, Elvira pudo conocer y experimentar un nuevo tipo de amistad que, a su parecer, se vería truncado por un noviazgo y posterior casamiento. Además, sentía que podía rechazar y postergar la propuesta a pesar de que Rizzi formaba parte de la comunidad y era bien visto por los padres de Elvira. No se sintió presionada por Santiago, ni por su familia y, en consecuencia, podemos decir que no existió sumisión patriarcal a tal solicitud de matrimonio, que continuaba siendo un acto sumamente importante todavía para la época. En otra oportunidad, cuando Elvira era tesorera del club, los socios miembros de la subcomisión de fútbol le solicitaron dinero para comprar botines y camisetas, ella se negó y les dijo que hicieran una rifa o alguna otra actividad para recaudar dinero. Finalmente, la CD les compró lo que solicitaban, pero ella había podido defender su postura. Es desde el club donde las mujeres comenzaron a transformar y hacer visibles esos cambios en las relaciones entre los géneros, pudiendo manifestar su disconformidad y, en más de una ocasión, tomar decisiones de relevancia desde sus cargos.

Durante toda la década, las socias y amigas de estas pudieron asistir a los denominados "bailes sociales" organizados por las distintas $\mathrm{CD}$. Al igual que al resto de los socios y sus amigos, se las invitaba mediante tarjetas confeccionadas en base a listas que surgían de las reuniones de los dirigentes del club. Sin lugar a dudas, estas reuniones de invitados especiales constituyeron el espacio de sociabilidad por excelencia de la élite local que, a su vez, contribuyó a su consolidación, definición y visibilidad en la comunidad.

Una actividad que amplió el universo masculino de la institución y que, a su vez, produjo cambios en las relaciones entre los sexos y las clases fue la práctica del fútbol. Los dirigentes tenían el poder de decisión sobre la admisibilidad de nuevos socios y lo hacían con ciertos mecanismos de control para aceptar solo a conocidos con rasgos socioeconómicos y culturales similares a los de ellos. Con todo, la nueva práctica deportiva en el club atrajo a una variedad de interesados en integrarse a la institución y la comisión

\footnotetext{
${ }^{30}$ Ibid.

${ }^{31}$ Elvira y Santiago se conocían porque él era sobrino político de una tía de ella. Él no participaba en el CJAC, sino que lo hacía en el Club "Bochas Sport Club" y era secretario en la Comuna: Ibid.
} 
81 | Eugenia Sánchez...

tuvo que replantearse los criterios para admitir a potenciales jugadores que no eran compatibles con el perfil de socio que buscaban. En consecuencia, se decidió crear dos categorías de miembros: los jugadores y los no jugadores. Los primeros solo participaron en el club jugando al fútbol, pagaban una cuota más baja que los otros, no abonaban la cuota de ingreso y llenaban una solicitud dirigida al presidente de la subcomisión que debía firmar el solicitante juntamente con el socio que lo presentaba. Finalmente, la CD decidía si se aprobaban o rechazaban las solicitudes. ${ }^{32}$ El fútbol, a la vez que abrió las puertas para el acceso de hombres de otra clase social, también lo hizo para aumentar las filas del sector dirigente. Integrantes de la clase propietaria de Caroya que hasta entonces no habían participado activamente en la institución se vieron atraídos e invitados por la CD para conformar la subcomisión. A su vez, las prácticas y torneos se convirtieron en momentos de tiempo compartido entre hombres de distintas clases y, en el caso de las competencias, también convocaron a las mujeres socias y no socias en calidad de espectadoras, todo lo cual contribuyó a que las redes de relaciones y espacios de sociabilidad se diversificaran y complejizaran.

Los "bailes populares" organizados por la CD y a donde era invitada toda la comunidad, también contribuyeron a un proceso de contacto y mixtura, tanto entre un "nosotros" y un "ellos", como entre mujeres y hombres caroyenses y de otras localidades aledañas. También se convirtieron en los lugares predilectos para la formación y propagación de chismes y rumores. Para lograr ingresar era fundamental ser bien visto por los socios que cobraban las entradas. Elvira sostiene que cuando no se permitía el ingreso a alguien era porque estaba "mal vestido". ${ }^{33}$ Generalmente, quienes se encontraban en las puertas de estos bailes eran dirigentes y se impedía la entrada a personas desconocidas para ellos. Un ejemplo del significado que esta clase de encuentros tenía para la sociedad caroyense se observa en lo relatado por Nelly. La entrevistada recuerda que conoció a su marido en un baile popular organizado por otro club contemporáneo al agrario, el Bochas Sport, en 1947 y que, como él era oriundo de Jesús María, le trajo muchos problemas bailar con él. A lo largo de su relato, enfatiza el peso y poder del rumor que, como se observará más adelante, condicionaba prácticas y decisiones, como la de bailar o no bailar, continuar o no una relación con alguien que formaba parte del "otros" y al que su familia y amigos calificaban de peligroso y "malo". También es significativo resaltar que la discriminación que observa Nelly nos está hablando de una sociedad que se encontraba en constante contacto y mezcla, ese "otros" está yendo a los bailes y está bailando y casándose con parte del "nosotros". En su caso, como seguramente en otros, la decisión de casarse con parte de ese "otros" implicó que tuviera que mudarse a otra localidad aledaña; pero lo trascendental es que Nelly tuvo márgenes de decisión sobre su futuro.

Sin lugar a dudas fueron los festejos de carnaval donde la asociación se comportó más

32 AROCD-CJAC, Libro I, núm. 48, 6 de diciembre de 1933, pp. 88-89.

${ }^{33}$ E. Trevisani, comunicación personal, 10 de febrero de 2014. Colonia Caroya. 
82 | Mujeres y sociabilidad pueblerina en Colonia Caroya...

flexiblemente en cuanto a las personas que convocaba y permitía ingresar. Estas fiestas comenzaron a organizarse en 1933 y, al año siguiente, se convocó a otros clubes de la zona -Club Caroya y Bochas Sport Club. ${ }^{34}$ La CD intentó organizar y concentrar en las instalaciones del club aquello que se hacía de manera espontánea en la sociedad caroyense. Estos eventos significaron para el club agrario una fuente de recaudación importante y también una oportunidad de posicionar a sus dirigentes en el espacio público caroyense ante el Estado y otras instituciones. Es probable que los bailes de carnaval conjuntamente organizados, ya sea con otros clubes o con el municipio, representaran los lugares de mayor diversidad sociológica, lo cual no quiere decir que se hayan dejado de establecer ciertos controles. En ellos, mujeres y hombres de distintas edades, clases y procedencias pudieron encontrarse y compartir un tiempo y espacio, siempre que pudieran costear la entrada y, una vez más, pasar los criterios de admisibilidad de quienes estuviesen a cargo de la puerta de entrada.

Un aspecto característico de la sociabilidad de Caroya, la importancia dada a un pasado en común ligado a la inmigración italiana, implicó prácticas y discursos xenófobos y endogámicos que no significaron un obstáculo para la participación de las mujeres caroyenses en una institución que implicaba compartir espacios y tiempos con los hombres. A su vez, el espacio, a pesar de las iniciativas de control sobre quiénes podían participar en él y de presentar caracteres propios de una sociedad patriarcal, se vio atravesado por un proceso de contactos y mixturas que vivía la sociedad. Estos cambios se reflejaron en el club y, a su vez, se aceleraron y adquirieron tintes propios en él. La experiencia de las mujeres en la novel asociación las llevó a ocupar cargos de importancia donde pudieron mostrar diferencias y desacuerdos con sus compañeros varones, a votar y ser elegidas. La sumisión femenina no fue total; las decisiones masculinas no se impusieron sin fisuras, sino que existieron espacios, posibilitados por la institución, para la disidencia y su manifestación.

\section{El chisme y el rumor como constituyentes de la vida de los pueblos}

Los vecinos de la localidad se conocían e identificaban entre sí por razones obvias que tienen que ver con la cantidad de habitantes, pero además compartían otros encuentros: por lo menos una vez por semana se reunían en la parroquia con motivo de la celebración de la misa; también se encontraban en la plaza y en la tienda de la cooperativa, entre otros lugares. Allí se veían, conversaban, observaban su vestimenta (la cual daba señales de su estatus) y se registraba con la mirada y los comentarios a todos los presentes, los ausentes y los acompañantes de cada uno. El "se dice" nos remite al plano del rumor y el chisme, fenómenos que se tornan vitales a la hora de analizar los vínculos construidos en un pueblo.

\footnotetext{
${ }^{34}$ AROCD-CJAC, Libro I, núm. 2, 11 de enero de 1933, p. 42; AROCD-CJAC, Libro I, núm. 49, 20 de diciembre de 1933, p. 92.
} 
Desde la antropología, los estudios sobre el rumor y el chisme son prolíficos. Pretendo alejarme de los primeros análisis surgidos durante la segunda posguerra donde se vinculaba a estos con una distorsión de la verdad, oponiéndolos a la noticia y a la objetividad (Allport y Postman, 1982) y retomar los trabajos de Margarita Zires Roldán (1995), quien pone en tensión esos postulados para atender al régimen de producción de aquello que es posible pensar y formular en un momento histórico determinado. En su investigación tiene en cuenta la dimensión cultural del rumor, le interesa el proceso de construcción de lo verosímil en una sociedad e invita a discutir y repensar la noción de verosimilitud. Sostiene que la manipulación, la deformación y la mentira ya no son características del rumor ni privilegio de la comunicación oral. Lo verosímil parte de la siguiente premisa: no todo se puede decir, es decir, hay cierta censura; sin embargo, también existe todo un conjunto de convenciones que establecen la producción de lo que sí se puede decir y el cómo. Reflexionar sobre qué es lo que se decía desde el orden, qué no podía decirse y qué estaba permitido, posibilita profundizar el estudio de las relaciones y vínculos construidos en un pueblo, ya que otorga más pistas sobre los modos y las formas en que estos se configuraron. Por lo tanto, algunas de las preguntas que intentaré responder son: ¿Qué era verosímil en Colonia Caroya durante los años '30? ¿Cómo se producían los rumores y chismes? ¿Qué relaciones se encuentran entre los espacios del club y los chismes y rumores esparcidos por la comunidad? ¿Qué nos informan estos fenómenos sobre las relaciones de género?

Antes de proseguir es necesario hacer una distinción entre el rumor y el chisme. Ana María Gorosito (2006) encuentra puntos de confluencia entre los dos fenómenos. Mientras el chisme es el estallido de algo que puede ser interpelado, desestimado y olvidado, el rumor viene a elevarlo y hacerlo correr como una verdad incuestionable. Esa verdad sentenciada por el rumor, afirma, va a acompañar al sujeto como una sombra insidiosa, "una suerte de predicción contenida socialmente hasta que ese chisme travestido en rumor la exhibe a la pública consideración (de modo que 'ya nos parecía que era de esa manera', 'en realidad siempre supe que algo había con Mengano', 'yo le desconfiaba alguna cosa')". Un ejemplo de chisme travestido en rumor que tuvo lugar en Caroya fue el que sentenció a una joven vecina de Nelly. La madre de la entrevistada, según ella, no le permitía juntarse con determinada vecina porque "se decía" que cuando volvía de pasear se quedaba encerrada con su novio en el auto. ${ }^{35}$ Aquí, se observa una de las "verdades incuestionables" que se esparcieron por el pueblo y configuraron las relaciones. Si se analiza este caso a partir de lo observado por Zires sobre la verosimilitud, se puede apreciar qué es lo plausible de ser creído y dicho: que se produzcan encuentros entre jóvenes de distinto sexos sin la presencia de adultos; algo que, vale aclarar, también sucedía en el club. El "se dice" proviene del anonimato y es transmitido a Nelly por su

\footnotetext{
${ }^{35}$ N. Copetti, comunicación personal, 23 de abril de 2015. Jesús María.
} 
84 | Mujeres y sociabilidad pueblerina en Colonia Caroya...

madre.

Conforme señala Pierre Mayol (1999), el chisme si bien promueve las relaciones entre vecinos, también tiende a abolir lo extraño a la comunidad, es una conjuración reiterada contra la alteración del espacio social. El chisme travestido en rumor que describí, está denunciando y condenando transformaciones que se estaban dando en la sociedad, esto es, la confluencia y contactos entre sexos en el espacio público. Mediante la herramienta del chisme, los actores resuelven situaciones, lo utilizan para interpretar permanentemente su realidad social y, de ese modo, redefinen sus posiciones, alianzas y conflictos. Así, afirma Fasano (2006), a través del chisme los actores participan en la dinámica de construcción de la vida social.

La llegada de una institución que invitaba a las mujeres a participar junto con los hombres fue, sin lugar a dudas, una novedad para los caroyenses y, por ello, desató algunos comentarios en la comunidad. Si bien hubo padres como los de Elvira que no se opusieron a que esta concurriera a las reuniones de la CD -solamente iba acompañada de su hermano a los bailes, aunque este fuese menor que ella- existieron vecinos que no querían que sus hijas se asociaran. Ante tal negativa, surgieron algunos rumores. Elvira nos comenta la actitud de un padre que sentenció a sus jóvenes hijas: "si ustedes se hacen socias no les voy a comprar vestido, no les voy a comprar más nada". ${ }^{36}$ Esta situación, que trascendió entre lo que se decía en la comunidad, posibilita acercarnos a la compleja realidad de esos años, a la heterogeneidad y matices en los discursos y prácticas que tuvieron lugar en una sociedad patriarcal. Así, la noción de feminidad que ligaba a las mujeres al ámbito privado y doméstico presentaba ciertos matices, indicadores de cambios en las relaciones entre géneros. Mientras existían y, seguramente preponderaban, nociones tradicionales que no permitieron a las mujeres participar en nuevos lugares, también se encuentran otras concepciones que, a pesar de que continuaban refiriéndose al rol hogareño de la mujer, no veían de forma negativa que formaran parte de un espacio compartido con hombres, a pesar de la circulación de comentarios que condenaba el hecho. Se debe tener en cuenta que la institución se desprendía de otra que para los padres contaba con un importante prestigio, la FAA.

Lo que trascendía en los comentarios que circulaban en la comunidad era lo que alguien había visto u oído. Nelly afirma que entre vecinos y familiares siempre se estaba hablando de caroyenses que supuestamente habían realizado algo que "estaba mal visto". Las actividades que tuvieron lugar en el CJAC favorecieron esa exposición y participación. Exponerse fue el recurso que emplearon los sectores más altos de la sociedad caroyense para definirse, mostrando lo que eran o pretendían ser ante el resto de la población y esperando que sus vecinos los identificaran y hablaran sobre su pertenencia a la institución. Los actos públicos sirvieron a dicho propósito. Un caso paradigmático fueron los festejos de agosto, celebración del aniversario de la FAA que comenzó a realizarse en 1936. Estos festejos se convirtieron en el evento más importante llevado a cabo

${ }^{36}$ E. Trevisani, comunicación personal, 20 de febrero de 2014. Colonia Caroya. 
por el club. Las fiestas consistían en una serie de juegos y torneos en los que participaban los socios; asimismo, delegados enviados por la FAA, directivos de la seccional local y de la cooperativa disertaban sobre los valores cooperativistas que debían respetarse para que "La Caroyense" funcionara. ${ }^{37}$ Además, estos festejos posibilitaron que las mujeres se mostraran como socias del club en el espacio público caroyense. Para atraer a ciertas mujeres, el club comenzó a hacerles un descuento considerable en las entradas si concurrían con el uniforme de la institución diseñado por la CD a principios de los '40, ${ }^{38}$ algo que solo algunas podían costear. La exclusividad que el club intentó dar a estas actividades, en las que se les garantizaban ciertos privilegios a los socios y socias, atrajo a los hijos de pequeños productores descendientes de italianos cercanos a la administración de la cooperativa y de la FAA. En 1940 ingresó el doble de socias que el año anterior -el mayor crecimiento de todo el período en estudio-y 10 de las 12 mujeres que se asociaron lo hicieron en la reunión siguiente a aquella en que se decidió que estas socias vestirían uniforme durante las fiestas de aniversario de la FAA. El pertenecer al club se transformó en algo digno de distinción, el uso de uniforme permitía marcar diferencias sociales y de género, haciéndolas visibles en actos públicos que trascendían en el tiempo y espacio a través de los rumores.

Los chismes y rumores que circulaban por Colonia Caroya informan sobre los cambios sobre la modalidad de encuentro entre jóvenes de distinto sexo y sobre la existencia de relaciones que desafiaban el discurso endogámico defendido por la comunidad. También nos hablan del rol desempeñado por instituciones como el CJAC en la propagación y formación de los mismos, donde el espacio, además de escenario, es también protagonista de lo que "se dice".

\section{Consideraciones finales}

El CJAC propició nuevos y modernos lugares de encuentro y participación para las mujeres caroyenses que afianzaron cambios en las interrelaciones juveniles, en los usos del tiempo libre y en las formas de vincularse con los hombres. Hacer foco en las mujeres y pensarlas como sujetos históricos que construyen, transforman y se ven condicionadas por los estilos de relacionarse entre ellas y con los varones, permite otorgar mayor contenido y complejidad a la noción de sociabilidad pueblerina y vislumbrar matices y síntomas de cambios en las relaciones.

Las caroyenses fueron encontrando en la institución un lugar de pertenencia y actuación que permitía que se las visibilizara y destacara dentro de la comunidad. La comunidad las conocía, pero ocasiones como actos y festejos donde podían lucir sus uniformes, permitió que se las identificara con instituciones muy importantes para la localidad,

${ }^{37}$ AROCD-CJAC, Libro I, núm. 85, 22 de julio de 1936, pp. 182-183.

38 ARECD-CJAC, Libro II, núm. 254, 2 de diciembre de 1942, p. 198. 
86 | Mujeres y sociabilidad pueblerina en Colonia Caroya...

tanto por su desarrollo económico como por su importancia social, cultural y política. El mirarse e identificarse era una práctica cotidiana en los espacios de sociabilidad del lugar, la pertenencia al CJAC posibilitó construir y/o reconstruir lo que se decía de alguien y mostrarse como parte de un "nosotros". A su vez, transitar y compartir los distintos espacios que se fueron habilitando desde la institución, llevó a estas mujeres a relacionarse con "otros", produciendo importantes cambios en su red de relaciones y experiencias de vida. También, su rol en el espacio público sufrió importantes cambios, pudieron participar de asambleas, votar y ser elegidas como miembros y resistirse a abandonar espacios frente a discursos y prácticas de una sociedad patriarcal que estaba en tensión con otras más modernas y democráticas.

\section{Referencias bibliográficas}

Aguado, A. (2000). Las relaciones de género y la nueva historia social. Identidad social y prácticas culturales. En Universitat de Valencia y Facultat de Geografia i Historia (Eds.), El Siglo XX. Balance y perspectivas. V Congreso de la Asociación de Historia Contemporánea (pp. 159-164). Valencia: Fundación Cañada Blanch.

Allport, G. y Postman, L. (1982). La psicología del rumor. Buenos Aires: Psique.

Arcondo, A. (1996). En el reino de Ceres. La expansión agraria en Córdoba 1870-1914. Córdoba: Ferreyra Editor.

Barrancos, D. (1999). Moral sexual, sexualidad y mujeres trabajadoras en el período de entreguerras. En F. Devoto y M. Madero (Dirs.), La Historia de la Vida Privada en la Argentina (pp. 199-225). Buenos Aires: Taurus.

Bontempo, P. y Queirolo, G. (2012). Las chicas modernas se emplean como dactilógrafas. Bicentenario. Revista de Historia de Chile y América, 11 (2), 51-76.

Bosch Alessio, C. (2012). Las mujeres en el mundo del trabajo, ciudad de Córdoba, 19041919. Prohistoria, 17, 51-76.

Bourdieu, P. (1990). El campo social y la génesis de las "clases". En P. Bourdieu, Sociología y cultura (pp. 281-310). México: Editorial Grijalbo.

Cedro, J. (2012). El negocio de la edición. Claridad 1922-1937. Primer coloquio sobre el libro y la edición. Recuperado de http://coloquiolibroyedicion.fahce.unlp.edu.ar. (19/11/2015).

Fasano P. (Ed.) (2006). De boca en boca. El chisme en la trama social de la pobreza. Buenos Aires: Antropofagia.

Gorosito, A. M. (2006). Prólogo. En P. Fasano (Ed.), De boca en boca. El chisme en la trama social de la pobreza (pp. 13-17). Buenos Aires: Antropofagia.

Lobato, M. (2007). Historia de las trabajadoras en la Argentina. Buenos Aires: Edhasa.

Mayol, P. (1999). Habitar. En M. De Certeau, L. Girad y P. Mayol (Coords.), La invención de lo cotidiano. 2: Habitar, cocinar (pp. 3-127). México: Universidad Iberoamericana.

Moreyra, B. (2000). Estado, mercado y sociedad. Córdoba 1820-1950. Tomo I. Córdoba: Centro 
87 | Eugenia Sánchez...

de Estudios Históricos "Prof. Carlos S. A. Segreti".

Núñez, M. (1978). Colonia Caroya, Cien años de historia. Córdoba: TA.P.AS.

Palermo, S. (2008). Dossier: El trabajo femenino en el siglo XX: nuevas miradas y planteos de la historia de la mujer y los estudios de género. Trabajos y Comunicaciones ( $2 a$ Época), 8 (34), pp. 99-110.

Remedi, F. (2014). Las trabajadoras del servicio doméstico: entre la subordinación y la negociación en una modernización periférica. Córdoba (Argentina), 1910-1930. Anuario de Historia Regional y de las Fronteras, 19 (2), 423-450.

Roggio, P. (2009). Trabajar, trabajar y trabajar.... Mujeres: reproducción y producción en el ámbito rural. Córdoba 1890 -1950. Estudio de caso: Colonia Caroya. Segundas jornadas nacionales de Historia Social. Recuperado de: http://www.cehsegreti.org.ar/historia-social-2/mesas\%20ponencias/MESA\%205/Ponencia\%20Patricia\%20ROGGIO.pdf. $(26 / 06 / 2015)$.

Salomón Chéliz, M. P. (2006). Laicismo, género y religión. Perspectivas historiográficas. Ayer, 61, 291-308.

Scott, J. (1990). El género: una categoría útil para el análisis histórico. Herramienta. Recuperado de: http://www.herramienta.com.ar/cuerpos-y-sexualidades/el-genero-unacategoria-util-para-el-analisis-historico.

$(01 / 02 / 2014)$.

Scott, J. (2000). La mujer trabajadora en el siglo XIX. En G. Duby y M. Perrot (Dirs.), Historia de las mujeres. El siglo XIX (pp. 427-461). Madrid: Taurus.

Segura Graiño, C. (2006). Recepción y evolución de la historia de las mujeres. Introducción y desarrollo en relación con la Historia de España. Vasconia, 35, 13-30.

Solveira, B. (2012). "La Caroyense" Cooperativa Vini Frutícola Agrícola Federal Limitada de Colonia Caroya. Un emprendimiento cooperativo integral. III Congreso Latinoamericano de Historia Económica y XXIII Jornadas de Historia Económica. Recuperado de: http://www.aahe.fahce.unlp.edu.ar/Jornadas/iii-cladhe-xxiii-jhe/ (01/10/2014).

Viel Moreira, L. (2005). Las experiencias de vida en el mundo del trabajo: los sectores populares del interior argentino (Córdoba, 1861-1914). Córdoba: Centro de Estudios Históricos "Profesor Carlos S.A. Segreti".

Zires Roldán, M. (1995). La dimensión cultural del rumor. De lo verdadero a los diferentes regímenes de verosimilitud. Comunicación y sociedad (24), 155-175.

Para citar este artículo:

Sánchez, Eugenia (2018). Mujeres y sociabilidad pueblerina en Colonia Caroya (Provincia de Córdoba). Club Juventud Agraria Colón, 1932-1942. Anuario de la Escuela de Historia Virtual, 13, 67-87. 